\title{
MÁRIO DE ANDRADE NO BRASIL E NO RIO DA PRATA: A TRADUÇÃO NA RECONFIGURAÇÃO DO GÊNERO CRÔNICA*
}

\author{
Rosario Lázaro Igoa \\ Universidade Federal de Santa Catarina \\ Florianópolis, Santa Catarina, Brasil
}

\begin{abstract}
RESUMO: O presente trabalho analisa a "poeticidade", segundo palavras de Antonio Candido (1980), da crônica brasileira a partir de 1930. A mudança de rumo é trabalhada segundo a tradução de uma parte da obra cronística de Mário de Andrade, Crónicas de melancolía eufórica (ALTER, 2016), e da sua inserção no Uruguai contemporâneo. Desta maneira, a tradução, enxergada do ponto de vista dos gêneros que relaciona, permite o diálogo entre duas tradições nas que 0 termo "crônica/crónica" não quer dizer exatamente o mesmo. Em função disso, busca-se estabelecer uma leitura de Mário de Andrade com Lima Barreto, outra afinidade que Candido sugere, mas também com dois cronistas relativamente contemporâneos a Andrade, mas de língua castelhana, como os argentinos Roberto Arlt e Alfonsina Storni. Finalmente, traçam-se linhas comparadas e pontos de quebra da evolução da "crônica/crónica" no Rio da Prata e no Brasil nas últimas décadas, quando o termo passa a denominar textos diferentes em termos estéticos e obtém fortuna crítica divergente.
\end{abstract}

PALAVRAS-CHAVE: Crônica brasileira; "Crónica" hispano-americana; Tradução literária; Mário de Andrade

\begin{abstract}
This paper analyzes the "poeticity", according to Antonio Candido (1980), of the Brazilian chronicle since 1930. The change of direction is examined through the translation of several Mario de Andrade's "crônicas", Crónicas de melancolía eufórica (ALTER, 2016), and its insertion in contemporary Uruguay. In this way, the translation, seen from the point of view of the genres it puts in contact, allows a dialogue between two traditions in which the term "crônica/crónica" does not mean exactly the same. As a result, I propose a reading of Mário de Andrade with Lima Barreto, another relationship that Candido raises,
\end{abstract}

\footnotetext{
* Parte deste trabalho foi apresentado no I Simpósio "Crônica: jornalismo, edição, tradução", realizado na Universidade Federal de Santa Catarina em dezembro de 2016.
} 
and also with two relatively contemporary chroniclers of Andrade, but from the Spanish domain: Argentinians Roberto Arlt and Alfonsina Storni. Finally, I aim to draw comparative lines and break points for the evolution of the "crônica/crónica" in Rio de la Plata and in Brazil in the last decades, when the term starts to refer to different texts in aesthetic terms and different critical approaches arise.

KEYWORDS: Brazilian "crônica"; Hispanic "crónica"; Literary Translation; Mário de Andrade 
A tradução provoca a reconfiguração dos gêneros nos sistemas literários que coloca em contato. A operação entre línguas não é só uma instância que pode chegar a modificar um determinado "sistema de procedimentos" (TOMACHEVSKI, 1982, p. 214), senão que se trata deum dos mais poderosos mecanismos de importação e exportação de fórmulas entre tradições literárias. $\mathrm{Na}$ conformação das literaturas deste lado do Atlântico, a história da crônica evidencia quão diferentes podem ser os processos de importação e apropriação das fórmulas europeias, neste caso do "espaço geográfico" (MEYER, 1992) do feuilleton, ou mesmo da chronique francesa, mas também daquela de origem espanhola e inglesa. A maestria de cronistas destacados, como Machado de Assis, José Martí, Rubén Darío ou José de Alencar, cada um deles com atributos próprios, contribuiu para que a crônica logo passasse a ser uma produção afastada de fórmulas imitativas. Isso sem entrar na pluralidade de questões que apenas a denominação "folhetim" suscitava no Brasil, por exemplo, e que Marlyse Meyer tão bem definiu:

[...] traduzir o folhetim, traduzir folhetins-variedades, publicar romance em folhetim, e escrever nos folhetins, constitui para os jovens brasileiros candidatos a escritores do primeiro terço do século XIX um verdadeiro laboratório. (MEYER, 1992, p. 129).

É justamente pela superposição de textos e tarefas que o "folhetim" traz, entendido no sentido midiático e de criação nessa matriz, que a polissemia não se esgotará quando os cronistas brasileiros comecem a denominar "crônica" o que até então era "folhetim", como explica Antonio Candido no conhecido ensaio intitulado "A vida ao rés-do-chão" (1980). Convém, contudo, tentar diferenciar as práticas textuais efetivas da nomenclatura que crítica, público e comunidade de cronistas utilizam, mesmo que as duas dimensões se retroalimentem. Tais dimensões, aliás, serão articuladas neste trabalho através da reflexão sobre a antologia em tradução.

$\mathrm{Na}$ dinâmica de mudança, hierarquia, evolução, desagregação e até "revolução" que Tomachevski adverte nos gêneros, o presente trabalho propõe analisar a "virada poética", segundo palavras de Candido, da crônica brasileira nos anos 30 do século XX, comparando-a com aquela do Rio da Prata na atualidade. A mudança de rumo no desenvolvimento de um gênero que até esse momento nem sequer tinha traços homogêneos no Brasil e no Rio da Prata, apesar de ser fruto de uma importação/re-apropriação bastante concomitante, será trabalhada a partir da tradução da obra cronística de Mário de Andrade e da sua inserção no Uruguai contemporâneo. Desta maneira, a tradução, do ponto de vista dos gêneros que relaciona, permite o diálogo crítico entre duas tradições nas que o termo "crônica/crónica" não quer dizer exatamente o mesmo. 


\section{INSUMOS DA CRÍTICA}

A poeticidade como traço constitutivo da moderna crônica brasileira é proposta pelo próprio Candido, no ensaio de 1980 já citado, originalmente escrito para ser o prólogo da antologia Para gostar de ler: crônicas. Cheio de grandes, e poéticas, máximas sobre o gênero crônica no Brasil, o texto tem o mérito de estabelecer uma genealogia tentativa do desenvolvimento desse gênero no Brasil, sobre a que voltarei a seguir. Além disso, Candido localiza o momento em que a crônica se transformaria em um "gênero bem nosso", ou seja, bem brasileiro, propondo que a consolidação no Brasil aconteceria nos anos 30, pois nesse momento:

[...] se afirmaram Mário de Andrade, Manuel Bandeira, Carlos Drummond de Andrade e apareceu aquele que de certo modo seria o cronista, voltado de maneira praticamente exclusiva para este gênero: Rubem Braga. (CANDIDO, 1992, p. 17)

Sabemos que esses cronistas tiveram no jornal um lugar privilegiado de publicação e interação com o público. Seja pelo reconhecimento no jornal ou em função dos livros que publicaram (ou de uma combinação desses e outros fatores), é possível observar que a fama dos modernistas de segunda geração seria um fator importante para a consolidação da crônica brasileira. Trata-se de um tipo de crônica escrita por uma geração de escritores conhecidos, ligada de forma estreita à intelectualidade do Rio de Janeiro, naquele momento capital do Brasil e cenário de uma vigorosa imprensa. Claro que há nesse panorama também cronistas mineiros, como Candido indica, e desde cedo a presença de Mário de Andrade escrevendo desde São Paulo (uma aproximação à história da crônica no Brasil revela produção deste gênero em todas as regiões).

O exercício aqui é, então, analisar como um determinado insumo da crítica, no caso o ensaio de Candido, ressalta uma veia da crônica brasileira que não se separa do fato desses cronistas serem escritores reconhecidos em outras áreas que não a da crônica, fundamentalmente na poesia. Em consequência, o que acontece quando esse modelo de crônica "poética" se encontra com a tradição da Argentina e do Uruguai é um assunto a explorar como consequência do ato tradutório, no sentido de reconfiguração do gênero mesmo.

Já no que diz respeito à genealogia, Candido não faz com que essa "moderna crônica brasileira" surja do além, senão que realiza o exercício de voltar sobre o século XIX para fazer esse panorama. A sucessão de cronistas traçada é bastante sugestiva pelo reconhecimento da "leveza" como vetor e estaria composta da seguinte maneira: 
[...] em José de Alencar, Francisco Otaviano e mesmo Machado de Assis, ainda se notava mais o corte de artigo leve. Em França Júnior já é nítida uma redução de escala nos temas, ligada ao incremento do humor e certo toque de gratuidade. Olavo Bilac, mestre da crônica leve, guarda um pouco do comentário antigo mas amplia a dose poética, enquanto João do Rio se inclina para o humor e o sarcasmo, que contrabalançam um pouco a tara do esnobismo. (CANDIDO, 1992, p. 16)

Por outro lado, Candido também localiza em Olavo Bilac a gratuidade na linguagem e a tendência lírico-humorística,

[...] a ponto de obrigá-lo a amainar a linguagem, descascá-la dos adjetivos mais retumbantes e das construções mais raras, como as que ocorrem na sua poesia e na prosa das suas conferências e discursos. Mas que encolhem nas crônicas. (CANDIDO, 1992, p. 16)

Simplicidade, alta dose poética, redução na extensão: esses parecem ser os traços do que seria ao longo do século XX a "moderna crônica brasileira". Mas há outro elemento a termos em conta, na medida em que sobre Drummond de Andrade e Rubem Braga, Candido afirma:

Tanto em Drummond quanto nele, observamos um traço que não é raro na configuração da moderna crônica brasileira: a confluência, na maneira de escrever, da tradição, digamos clássica, com a prosa modernista. Esta fórmula foi bem manipulada em Minas (onde Rubem Braga viveu alguns anos decisivos); e dela se beneficiaram os que surgiram nos anos 40 e 50, como Fernando Sabino e Paulo Mendes Campos. É como se (imaginemos) a linguagem seca e límpida de Manuel Bandeira, coloquial e corretíssima, se misturasse com o ritmo falado da de Mário de Andrade, com uma pitada do arcaísmo programado pelos mineiros. (CANDIDO, 1992, p. 17)

Desta maneira, a chave da "moderna crônica brasileira" também estaria na perda do tom argumentativo, e no ganho no território do poético. A esse respeito, Manuel Bandeira faz em uma crônica intitulada "Poema desentranhado" um exercício de recomposição da poesia de Augusto Frederico Schmidt que ele afirma encontrar em um parágrafo de prosa daquele poeta e o resultado termina sendo sim um poema, mas na própria crônica de Bandeira. Para orientar-se nessa tarefa de desvendar a poesia na prosa, Bandeira diz guiar-se pela existência de "uma imagem insólita ou por um encontro encantatório de vocábulos" (BANDEIRA, 1966, p. 88). Tanto pelas imagens, quanto pelas colocações originais, a crônica rio-platense se assemelha à brasileira. Assim, a definição de Bandeira serviria também para abordar crônicas da poetisa argentina Alfonsina Storni, como "Un baile familiar", publicada primeiramente em 9 de maio de 1919, com particular ritmo e até disposição espacial das orações: 
A las seis de la mañana la sala de baile está vacía.

Las sillas en desorden, el piano abierto, algunas flores caídas en el piso...

Flota en el aire un olor a polvos, a perfumes, a cosméticos, a brillantina, a seres de raza blanca...

Sueñan las muchachas cosas raras; comentan los muchachos pequeños detalles.

Nada.

Un baile honesto de familia.

Más peligrosos que esto suelen ser ciertos versos de mujer... (STORNI, 1998, p. 37)

Ou antes ainda, nas crônicas de Roberto Arlt dos anos 30 e publicadas nas Aguafuertes porteñas, em que lemos trechos de alta poeticidade:

En el cubo negro de la noche, la ventana iluminada, como un ojo, vigila las azoteas y hace levantar la cabeza de los trasnochadores que de pronto se quedan mirando aquello con una curiosidad más poderosa que el cansancio. (ARLT, 1993, 79)

Mas se em Storni ou em Arlt encontramos essa certa poeticidade em crônicas cotidianas, no decorrer do século XX, o rumo predominante do gênero e do olhar da crítica será outro. Nas crônicas de Rodolfo Walsh, e mais em diante com o "jornalismo narrativo" de Leila Guerriero, Martín Caparrós e Cristian Alarcón, " mesmo com achados em termos de linguagem, a importância do político e do social se confirma. Aliás, como propõe Susana Rotker em La invención de la crónica (2005), essa preocupação pelo social e pelo político já está no século XIX em José Martí, e não surgiria como uma simples cópia do new journalism norte-americano.

\section{ANTOLOGIA E COMO ELA É LIDA}

A organização e tradução da antologia Crónicas de melancolía eufórica (ALTER, 2016) permite realizar esta leitura comparativa da crônica no domínio do Brasil e do Rio da Prata, tomando como ponto de inflexão a reconfiguração de gêneros que acontece na mediação de antologização e tradução. Mais ainda, suscita perguntas tais como: como se recebe uma antologia de crônicas brasileiras de começo do século XX no Uruguai contemporâneo? O que seria crônica nesta contemporaneidade?

Da parte que pode ser respondida, no que me correspondeu como tradutora e co-organizadora da antologia, esse problema suscitou redigir um prólogo breve,

\footnotetext{
1 Para uma discussão mais aprofundada sobre as diferenças entre a crônica e a crítica brasileira e a hispano-americana, ver: Lazaro Igoa, Rosario. "La arista brasileña de la crónica iberoamericana: apuntes sobre una incorporaciónnecessária". Anales de Literatura Hispanoamericana. Vol. 44. 2015, p. 125-137.
} 
mas que servisse como introdução da obra para o leitor rio-platense. Os objetivos buscados nesse texto foram: estabelecer a nuance de diferença entre o gênero das duas tradições que estavam em contato; localizar Mário de Andrade na ponte que a tradução estava propondo; explicar a fixação do texto com base na edição Táxi e crônicas no Diário Nacional (1976) e no próprio jornal; e fundamentar sucintamente a estratégia de tradução, relacionada, evidentemente, com a dimensão editorial do projeto. As crônicas de Mário de Andrade foram apresentadas sim como "crónicas", palavra que já está presente no título do volume, o que manifesta a intenção de fazer também uma ponte com a extensa tradição anterior a Walsh, Guerriero ou Caparrós, aquela linha de cronistas como Domingo F. Sarmiento, Daniel Muñoz, Soiza Reilly, e Last Reason, dentre muitos outros do século XIX e XX. A tradução de Mário de Andrade suscita, ou poderia suscitar, novas releituras dessa tradição.

Mas o gesto de tradução não se esgota na reconfiguração do gênero, mas também habilita uma aproximação que sugere afinidades na poeticidade prévia de outros cronistas brasileiros. Não desmerecendo o potencial renovador $\mathrm{e}$ experimental de Mário de Andrade, a irrupção da poesia no cotidiano já era evidente em um cronista pouco anterior, como Lima Barreto, com um estilo diferente, corrosivo, e comprometido no político. Há uma crônica dele que me interessa destacar, já quase nos anos 1920, e que evidencia uma sofisticação nas ferramentas estilísticas: o tom segue sendo crítico, mas a escrita ganha leveza e precisão. Assistindo um enterro, Lima Barreto comenta:

Em geral assisto a passagem desses cortejos fúnebres na Rua José Bonifácio canto da Estrada Real. Pela manhã gosto de ler os jornais num botequim que há por lá. Vejo os Órgãos, quando as manhãs estão límpidas, tintos com a sua tinta especial de um profundo azul-ferrete e vejo uma velha casa de fazenda que se ergue bem próximo, no alto de uma meia laranja, passam carros de bois, tropas de mulas com sacas de carvão nas cangalhas, carros de bananas, pequenas manadas de bois, cujo campeiro cavalga atrás sempre com o pê direito embaralhado em panos. (LIMA BARRETO, 2004, p. 553)

Mais ainda: a dose poética é também evidente nas crônicas de Pedro Kilkerry, publicadas em Salvador no começo do século XX, e intituladas como série "Quotidianas" e recuperadas por Augusto de Campos em ReVisão de Kilkerry (1985). Herméticas, mas profundamente criativas, essas crônicas apresentam inovações sintáticas, imagens perturbadoras e originais neologismos, que ampliam a genealogia na qual se insere Mário de Andrade.

\section{À GUISA DE REFLEXÃO}

Como foi possível advertir, na busca de linhas comparadas e pontos de quebra na evolução da "crônica/crónica" no Rio da Prata e no Brasil nas últimas 
décadas, é chave compreender quando o termo passa a denominar textos diferentes em termos estéticos e obtém fortuna crítica divergente.

Em função deste breve percurso comparativo, é possível fazer alguns comentários finais. Se a crônica ganha seu caráter "brasileiro" nos anos 30, isso não é um processo que acontece de um momento para outro, senão que se apoia em cronistas anteriores, como Lima Barreto, ou até Olavo Bilac. Penso que poderíamos traçar até José de Alencar essa arqueologia do gênero no Brasil, a dose poética, o caráter metalinguístico, a leveza.

Ao mesmo tempo, é graças ao reconhecimento dos modernistas de segunda geração que a crônica no Brasil ganha a importância e características que possui na atualidade. A crônica brasileira goza de amplo reconhecimento crítico se compararmos com o cenário do Rio da Prata, pelo menos até há pouco tempo atrás, assim como tem muito a ver com a obra dos modernistas de segunda geração nos jornais. Talvez seja mais importante perguntar não tanto se a crônica é um gênero brasileiro, senão qual a poética da crônica brasileira, suas diferenças e semelhanças com a crônica do domínio hispânico. O jornalismo narrativo, estudado por Rotker, será o rumo da "crónica" no âmbito hispânico, mas sem deixar de lado textos de corte impressionista, mais escassos e não os únicos na tradição da crônica do lado castelhano da fronteira, com os quais Mário de Andrade estabelece um diálogo.

\section{REFERÊNCIAS}

ÁLVAREZ FERRETJANS, Daniel. Historia de la prensa en el Uruguay: desde La estrella del Sur a Internet. Montevideo: Editorial Fin de Siglo, 2008.

ANDRADE, Mário de. Crónicas de melancolía eufórica. Leonardo Cabrera y Rosario Lázaro Igoa (Org). Traducción R. Lázaro Igoa. Montevideo: Alter, 2016.

. Táxi e Crônicas no Diário Nacional. Telê Porto Ancona Lopez. (Org. e prólogo). São Paulo: Secretaria da Cultura, 1976.

ARLT, Roberto. "Ventanas iluminadas". In: El Jorobadito. Aguafuertes porteñas. El criador de gorilas. Buenos Aires: Colihue, 1993, p. 78-81.

BANDEIRA, Manuel. Os Reis Vagabundos e mais 50 crônicas. Rio de Janeiro: Editora do autor, 1966.

CANDIDO, Antonio. "A vida ao rés-do-chão". In: CANDIDO, Antonio et al. A Crônica. O gênero, sua fixação e suas transformações no Brasil. Campinas: Editora Unicamp; Rio de Janeiro: Fundação Casa de Rui Barbosa, 1992, p. 13-22.

Campos, Augusto de. ReVisão de Kilkerry. $2^{\mathrm{a}}$ ed. São Paulo: Brasiliense, 1985. 
LAZARO IGOA, Rosario. Crónica brasileña del siglo XIX y principios del siglo $X X$ en castellano. Tese. UFSC, Programa de Pós-Graduação em Estudos da Tradução, Florianópolis, 2016. Acesso em: 1 jul. 2017. Disponível em: $<$ https://repositorio.ufsc.br/xmlui/handle/123456789/167919>.

LIMA BARRETO, Afonso Henriques de. Toda crônica. Beatriz Resende e Rachel Valença (Org.). Vol. 2. Rio de Janeiro: Agir, 2004.

MEYER, Marlise. "Voláteis e versáteis. De variedades e folhetins se fez a chronica". In: CANDIDO, Antonio et al. A Crônica: o gênero, sua fixação e suas transformações no Brasil. Campinas: Editora Unicamp; Rio de Janeiro: Fundação Casa de Rui Barbosa, 1992, p. 93-133.

ROTKER, Susana. La invención de la crónica. México DF: Fondo de Cultura Económica, 2005.

STORNI, Alfonsina. Nosotras y la piel. Selección de ensayos de Alfonsina Storni. Mariela Méndez, Graciela Queirolo y Alicia Salomone (Compilación y prólogo). Buenos Aires: Alfaguara. 1998.

TOMACHEVSKI, Boris. "Los géneros literarios". In: Teoría de la literatura. Trad. Marcial Suárez. Madrid: Akal, 1982, p. 211-269.

Rosario Lázaro Igoa RosiLazaro@gmail.com

Recebido em: 11/9/2017

Aceito em: 23/2/2018

Publicado em Abril de 2018 